\title{
ORIGINAL RESEARCH \\ Is Brain Maturation Comparable in Fetuses and Premature Neonates at Term Equivalent Age?
}

A. Viola

S. Confort-Gouny

J.F. Schneider

Y. Le Fur

P. Viout

F. Chapon

S. Pineau

P.J. Cozzone

N. Girard

BACKGROUND AND PURPOSE: Improved knowledge of brain maturation in fetuses and premature neonates is crucial for the early detection of pathologies and would help determine whether MR data from the premature brain might be used to evaluate fetal maturation. Using diffusion-weighted MR imaging and ${ }^{1} \mathrm{H}-\mathrm{MR}$ spectroscopy, we compared cerebral microstructure and metabolism in normal in utero fetuses imaged near term and premature neonates imaged at term equivalent.

MATERIALS AND METHODS: Forty-eight subjects were investigated: 24 in utero fetuses (mean gestational age, $37 \pm 1$ weeks) and 24 premature neonates (mean postconceptional age, $37 \pm 1$ weeks). $A D C$ values were measured in cerebellum, pons, white matter, brain stem, basal ganglia, and thalamus. MR spectroscopy was performed in deep white matter.

RESULTS: Mean ADC values from fetuses and premature neonates were comparable except for the pons and the parietal white matter. ADC values were lower in the pons of premature neonates, whereas greater values were found in their parietal white matter compared with fetuses. Proton MR spectroscopy showed higher levels of $\mathrm{NAA} / \mathrm{H}_{2} \mathrm{O}, \mathrm{Glx} / \mathrm{H}_{2} \mathrm{O}, \mathrm{tCr} / \mathrm{H}_{2} \mathrm{O}$, and $\mathrm{m} / \mathrm{ns} / \mathrm{H}_{2} \mathrm{O}$ in premature neonates compared with fetuses.

CoNCLUSIONS: Our study provides evidence of subtle anomalies in the parietal white matter of healthy premature neonates. In addition, the reduced $A D C$ values in the pons together with the increased levels of $\mathrm{NAA} / \mathrm{H}_{2} \mathrm{O}, \mathrm{tCr} / \mathrm{H}_{2} \mathrm{O}$, and $\mathrm{Glx} / \mathrm{H}_{2} \mathrm{O}$ in the centrum semiovale suggest a more advanced maturation in some white matter regions. Our results indicate that MR data from the premature brain are not appropriate for the assessment of the fetal brain maturation.

ABBREVIATIONS: $A D C=$ apparent diffusion coefficient; Cho = choline; $\mathrm{DWI}=$ diffusion-weighted $\mathrm{MR}$ imaging; $\mathrm{GA}=$ gestational age; $\mathrm{Glx}=$ glutamine plus glutamate; ${ }^{1} \mathrm{H}-\mathrm{MR}=$ proton $\mathrm{MR}$; HASTE = half-Fourier acquired single-shot turbo spin-echo; Lac = lactate; MRI = MR imaging; mlns = myo-inositol; NAA $=N$-acetylaspartate; $\mathrm{PCA}=$ postconceptional age; $\mathrm{PN}=$ premature neonate; PRESS = point resolved spatially localized spectroscopy; $\mathrm{ROI}=$ region of interest; $\mathrm{Tau}=$ taurine; $\mathrm{tCr}=$ total creatine; $\mathrm{VOI}=$ volume of interest

A mong MR techniques, DWI and MR spectroscopy are considered appropriate and accurate techniques for the evaluation of brain maturation. DWI enables the assessment of macroscopic water diffusion and thereby tissue microstructure. Previous studies of preterm neonates, term neonates, and children have shown correlation between decreased ADC and progressive brain maturation. ${ }^{1-5}$ These changes precede those seen on conventional MR images and provide early information on tissue organization. ${ }^{6}$

${ }^{1} \mathrm{H}-\mathrm{MR}$ spectroscopy is an efficient technique for obtaining noninvasive metabolic information from the human brain and has become a powerful diagnostic tool in the pediatric population, especially for the detection of hypoxic encephalopathy, leukoencephalopathies, and inborn errors of metab-

Received September 13, 2010; accepted after revision January 2, 2011.

From the Centre de Résonance Magnétique Biologique et Médicale Unité Mixte de Recherche-Centre National de la Recherche Scientifique 6612 (A.V., S.C.-G., Y.L.F., P.V., P.J.C., N.G.), Faculté de Médecine, Université de la Méditerranée, Marseille, France; Department of Pediatric Radiology (J.F.S.), University Children's Hospital UKBB, Basel, Switzerland; and Service de Neuroradiologie (F.C., S.P., N.G.), Hôpital la Timone, Université de la Méditerranée, Marseille, France.

This study was supported by the Centre National de la Recherche Scientifique.

Please address correspondence to Nadine Girard, PhD, Service de Neuroradiologie, Hôpital la Timone, Université de la Méditerranée, 264 rue Saint-Pierre, 13385 Marseille CEDEX 05, France; e-mail: nadine.girard@ap-hm.fr

Indicates open access to non-subscribers at www.ajnr.org

http://dx.doi.org/10.3174/ajnr.A2555

olism. ${ }^{7}$ It also provides essential metabolic information on the developing brain ${ }^{8-10}$ and has been successfully applied to in utero cerebral maturation evaluation as well. ${ }^{11-15}$

The aim of this study was 2 -fold. The first objective was to compare brain maturation between in utero fetuses imaged near term and premature neonates examined at term equivalent by using an approach combining DWI with ADC maps, and proton MR spectroscopy to evaluate structural and metabolic changes between both populations. The protocol of spectroscopy included ${ }^{1} \mathrm{H}$-MR spectroscopy performed at short and long TE, because long TEs allow unambiguous detection of lactate signal owing to lipid signal suppression, which may be important in the context of prematurity. ${ }^{16} \mathrm{~A}$ better understanding of how normal cerebral maturation in fetuses and premature neonates evolves is essential for the early detection of pathologic alterations and the assessment of therapeutic interventions. The second aim of this study was to assess whether cerebral microstructural and metabolic data obtained from premature neonates by using MR imaging and MR spectroscopy techniques might help evaluate normal brain maturation in utero.

\section{Materials and Methods}

\section{Subjects}

The cohort included a group of 24 fetuses imaged in utero near term (mean age, $37 \pm 1$ week GA; range, 36-39 weeks GA; Fig 1) and a 


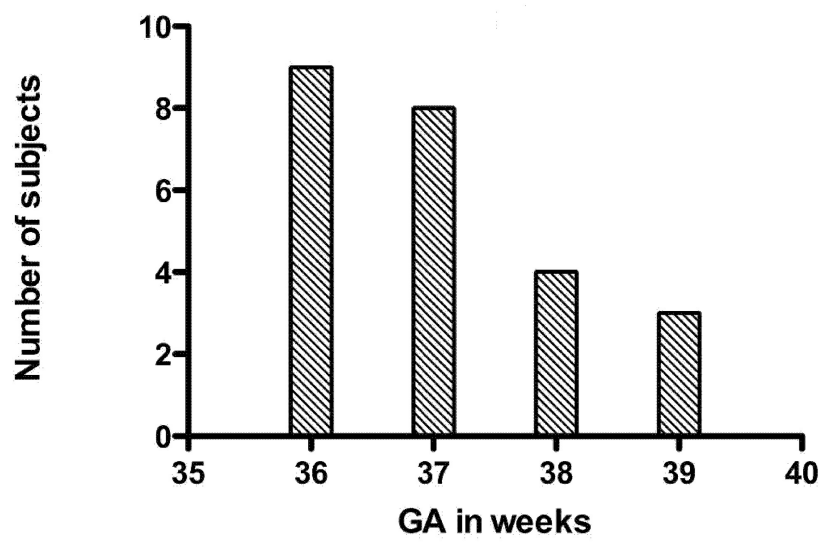

Age of PN at birth

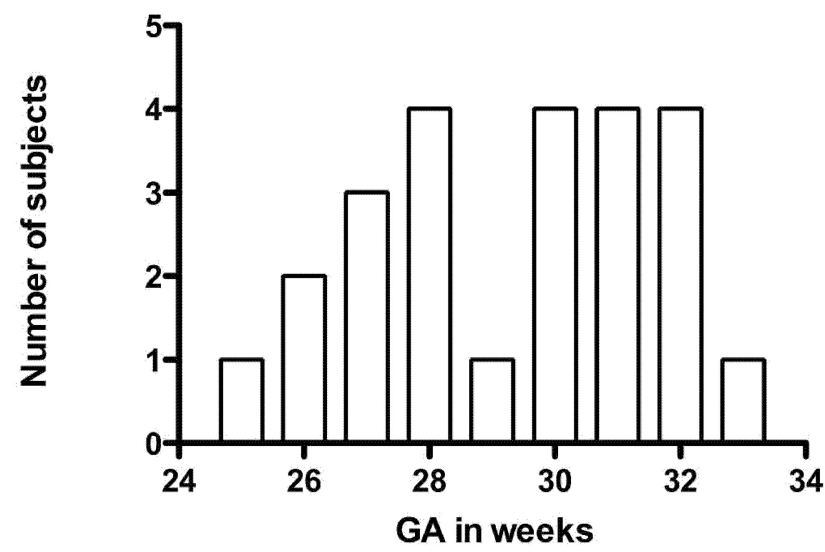

Fig 1. Age distribution of fetus and PN. The GA and PCA are expressed in weeks.

group of 24 premature neonates (mean age at birth, $29 \pm 2$ weeks GA; range, 25 to 33 weeks GA) imaged between 36 and 39 weeks PCA (mean age, $37 \pm 1$ week PCA; Fig 1 ). The statistical comparison of the ages at MR imaging by using the Mann-Whitney $U$ test did not show any significant difference between both groups $(P=.1779)$. Fetuses were referred for suspicion of central nervous system malformation that was ruled out by MR imaging and considered morphologically normal. Premature neonates were imaged as part of the routine morphologic evaluation before discharge from hospital near term and were considered morphologically and clinically normal. All premature neonates had an appropriate weight for age at birth. Cases with clinical evidence of neonatal infection and birth asphyxia were excluded from the study as well as those with geminal matrix hemorrhage, ventriculomegaly, or hydrocephalus.

\section{MR Imaging and MR Spectroscopy Protocol}

MR examinations were performed on a clinical MR system operating at 1.5T (Symphony Maestro Class; Siemens, Erlangen, Germany).

Fetal Brain Exploration. Body phased array coils (4 elements) were used in combination with spinal coils (2-3 elements). The 4 anterior elements were placed transverse joining the posterior elements to optimize signal intensity homogeneity.

The standard MR imaging protocol included HASTE images and gradient-echo T1-weighted images following the 3 planes of the fetal head. DWI was performed with an axial multisection multirepetition
Age of PN at MRI

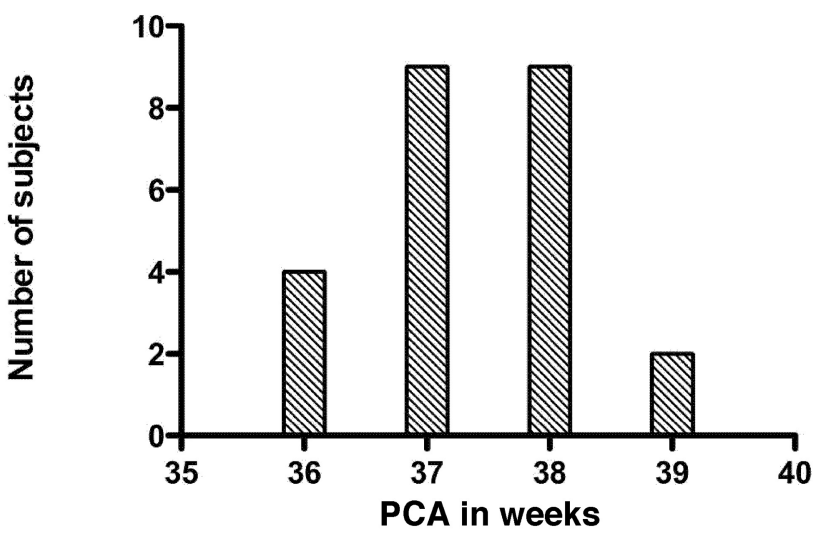

spin-echo echo-planar technique ( $\mathrm{TR}=3200 \mathrm{~ms}$; $\mathrm{TE}=102 \mathrm{~ms}$; section thickness $=4 \mathrm{~mm} ; 3$ averages per image; FOV $=350 \times 350 \mathrm{~mm}^{2}$; acquisition matrix, $128 \times 128)$. Diffusion was measured in 3 orthogonal directions from 3 values of $b\left(b=0,500\right.$, and $\left.1000 \mathrm{~s} / \mathrm{mm}^{2}\right)$, with a total acquisition time of 1 minute 40 seconds. DWI and ADC maps were obtained for the 24 subjects (diffusion tensor imaging was not obtained for these 2 groups).

Localized brain MR spectroscopy was performed following the MR imaging protocol by using a PRESS sequence with short and long TE (30 and $135 \mathrm{~ms}$, respectively) by the single-voxel technique. The size of the VOI located in the centrum semiovale was $4.5 \mathrm{~cm}^{3}(2 \times$ $\left.1.5 \times 1.5 \mathrm{~cm}^{3}\right)$. The voxel included the parietal, central, and precentral areas (Fig 2). At each TE, the sequence was performed with and without water saturation $(\mathrm{TR}=1500 \mathrm{~ms}, 256$ averages for $\mathrm{TE}=30$ $\mathrm{ms}$, and 278 averages for $\mathrm{TE}=135 \mathrm{~ms}$; acquisition time, 7 minutes 3 seconds and 6 minutes 31 seconds, respectively). The spectra could be recorded in 20 cases at short TE and in 19 cases at long TE.

Brain Exploration of Premature Neonates. An 8-channel head coil was used for these examinations. DWI was performed with a sequence similar to that used for fetuses $\left(\mathrm{FOV}=240 \times 240 \mathrm{~mm}^{2}\right)$. DWI and ADC maps were obtained for the 24 premature neonates. The MR spectroscopy protocol was identical to that used for fetuses in terms of sequence, size, and location of the VOI (Fig 2). However, the number of averages used for neonates was lower (64) compared with fetal studies because the filling factor of the head coil is better than 

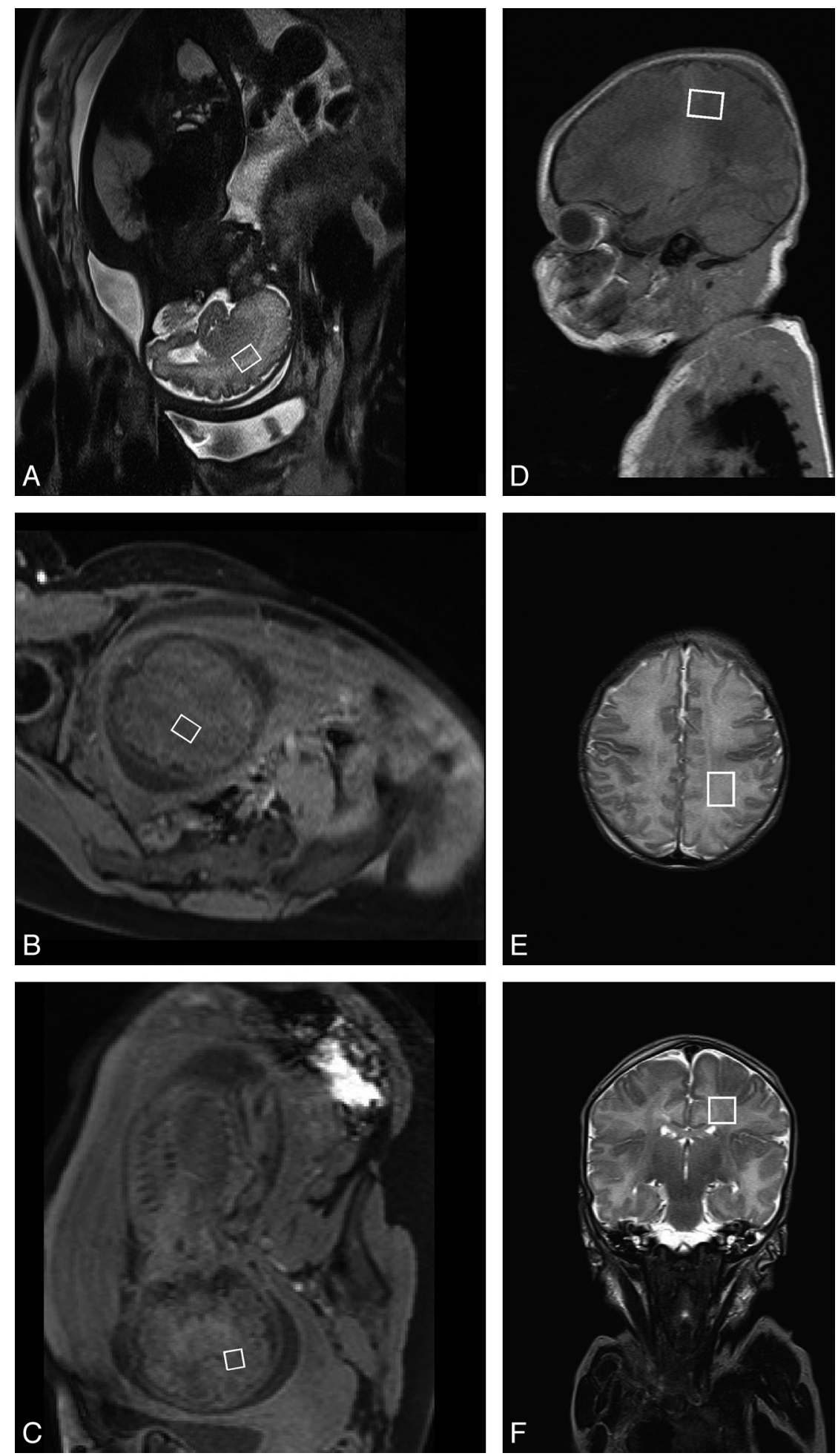

Fig 2. Localization of the voxel for ${ }^{1} H-M R$ spectroscopy. $A-C$, fetus; $D-F$, PN.

that of the body coil. Brain spectra were obtained for 20 premature neonates at all TEs.

\section{MR Data Processing}

DWI Data. DWI and the averaged ADC maps were automatically generated by using Siemens software. Circular single-sized ROIs of 5-mm radius were carefully placed to avoid contamination from adjacent CSF. ADC values were measured in cerebellum; pons; thala- mus; basal ganglia; deep white matter of temporal, occipital, frontal, and parietal lobe; and centrum semiovale. In this latter location, the ROI was placed below the central sulcus.

MR Spectroscopy Data. After zero-filling and exponential filtering, spectra were fitted in the time domain by using a metabolic data base derived from MR spectroscopy acquisitions of aqueous model solutions of pure metabolites by using the AMARES-MRUI FORTRAN code ${ }^{17}$ included in a homemade software developed under IDL 

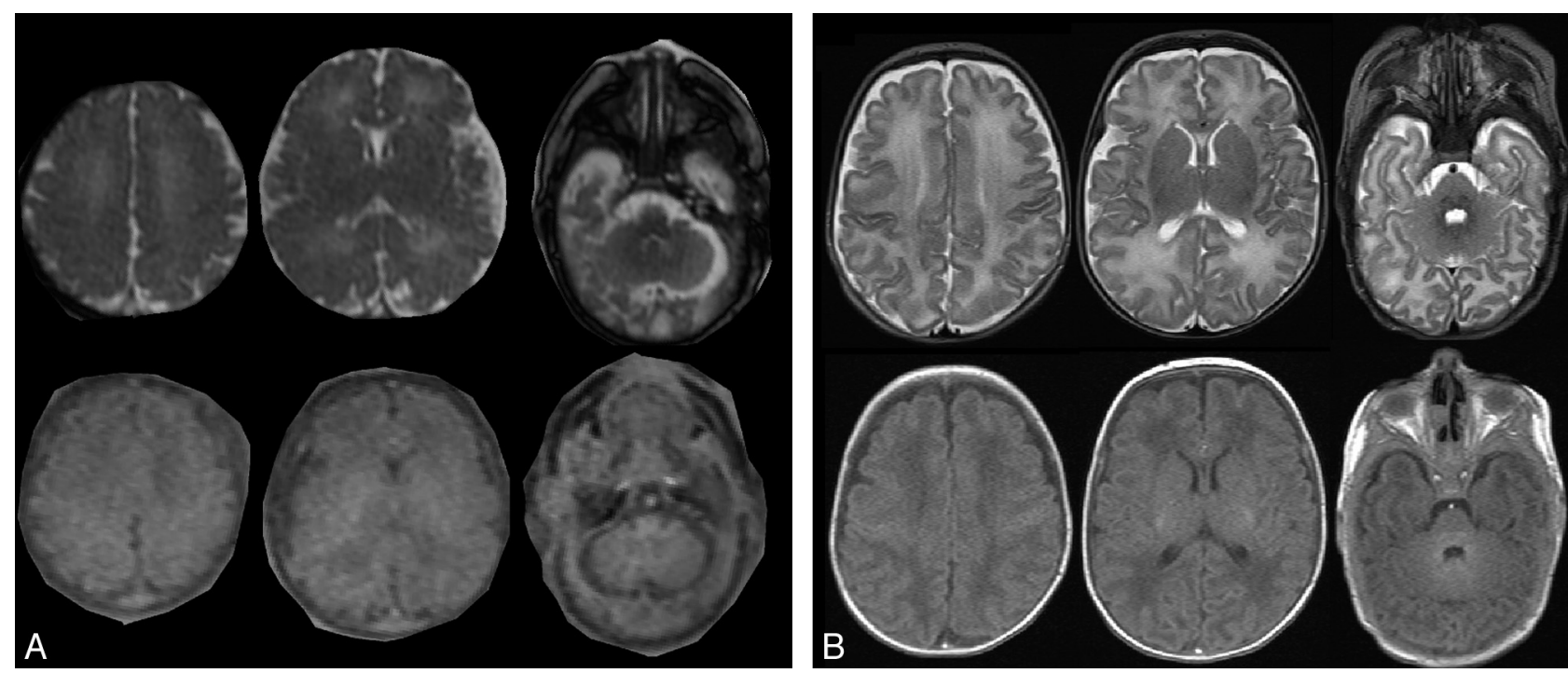

Fig 3. Typical axial T1- and T2-weighted MR imaging from an in utero fetus and a PN. A, Brain MR imaging of a fetus explored at 37 weeks GA. Axial T2-weighted images (HASTE sequence; top row). Axial T1-weighted images (bottom row). B, Brain MR imaging of a PN born at 27 weeks GA and explored at 38 weeks PCA. Top row, Axial T2-weighted images. Bottom row, Axial T1-weighted images. Images were obtained at the level of the centrum semiovale, basal ganglia, and posterior fossa (from left to right).
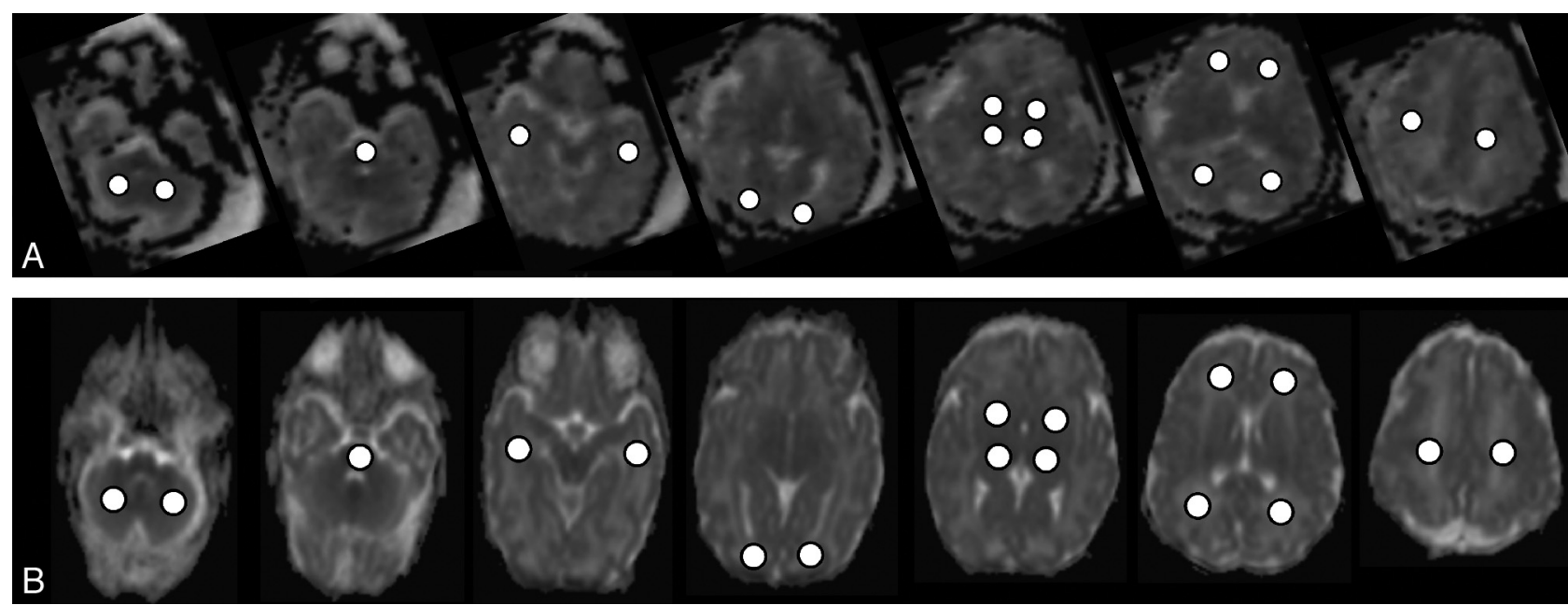

Fig 4. Typical cerebral $\mathrm{ADC}$ maps from a fetus and a preterm neonate. Row $A, A D C$ maps of a fetus ( $G A=36$ weeks). Row $B, A D C$ maps of a preterm neonate (PCA $=36$ weeks). The location of the ROls within all analyzed brain areas is displayed within the images (for each row from left to right: cerebellum, pons, temporal white matter; occipital white matter, thalamus and basal ganglia; frontal and parietal white matter, centrum semiovale).

environment (Interactive Data Language Research System, Boulder, Colorado). The signals of brain metabolites NAA, tCr, Cho-containing compounds, Glx, mIns, and Tau were normalized by using water signal intensity as an internal reference. ${ }^{12}$ The results are expressed as ratios of the relative area of each metabolite signal intensity to the water signal intensity obtained at long TE to avoid a T2 effect, and as ratios of metabolites.

\section{Statistical Analysis}

A parametric analysis was used, because all values tested (age, ADC value, and metabolic ratio) were coming from normal distributions (d'Agostino and Pearson omnibus normality test). ADC values obtained from various regions of the left and right hemispheres were compared by using a 2-tailed paired Student $t$ test. The comparison of ADC values, or metabolic ratios, between both groups of subjects for each brain region was performed by using a 2-tailed unpaired $t$ test. Statistical analysis was performed by using Prism version 5.00
(GraphPad Software, San Diego, California). Values are reported as means \pm SEM. Values of $P<.05$ are considered significant.

\section{Results}

\section{Comparison of ADC Values between Fetuses and Premature Neonates}

The fetuses and PNs did not show any evidence of lesion at conventional MR imaging (Fig 3). No significant difference was observed among ADC values obtained from the different regions of the left and right hemispheres; therefore, these values were averaged before comparison between the groups of fetuses and premature neonates.

In both groups, $\mathrm{ADC}$ values were lower in the pons, cerebellum, thalamus, and basal ganglia (range, $0.98-1.26 \times 10^{-6}$ $\mathrm{mm}^{2} / \mathrm{s}$ ) compared with supratentorial white matter regions (range, $1.44-1.77 \times 10^{-6} \mathrm{~mm}^{2} / \mathrm{s}$; Fig 4 and Table 1). Statisti- 
Table 1: Comparison of ADC values in fetuses and PNs

\begin{tabular}{lccc}
\hline Cerebral Structure & $\begin{array}{c}\text { Fetuses }(n=24) \text { ADC } \\
\left(\times 10^{-6} \mathrm{~mm}^{2} / \mathrm{s}\right)\end{array}$ & $\begin{array}{c}\text { PNs }(n=24) \text { ADC } \\
\left(\times 10^{-6} \mathrm{~mm}^{2} / \mathrm{s}\right)\end{array}$ & $\begin{array}{c}\text { Unpaired } t \text { Test, } \\
P \text { Value }\end{array}$ \\
\hline Cerebellum & $1.20 \pm 0.02$ & $1.19 \pm 0.02$ & .6839 \\
Pons & $1.07 \pm 0.02$ & $0.98 \pm 0.02$ & .0008 \\
Thalamus & $1.14 \pm 0.02$ & $1.10 \pm 0.01$ & .1251 \\
Basal ganglia & $1.26 \pm 0.02$ & $1.21 \pm 0.01$ & .0869 \\
Temporal white matter & $1.53 \pm 0.03$ & $1.57 \pm 0.02$ & .2257 \\
Occipital white matter & $1.50 \pm 0.03$ & $1.56 \pm 0.02$ & .1236 \\
Frontal white matter & $1.75 \pm 0.02$ & $1.77 \pm 0.03$ & .4981 \\
Parietal white matter & $1.66 \pm 0.03$ & $1.77 \pm 0.03$ & .0172 \\
Centrum semiovale & $1.44 \pm 0.03$ & $1.44 \pm 0.03$ & .8654 \\
\hline
\end{tabular}

Note:-Data are mean \pm SEM.

$\mathrm{TE}=30 \mathrm{~ms}$
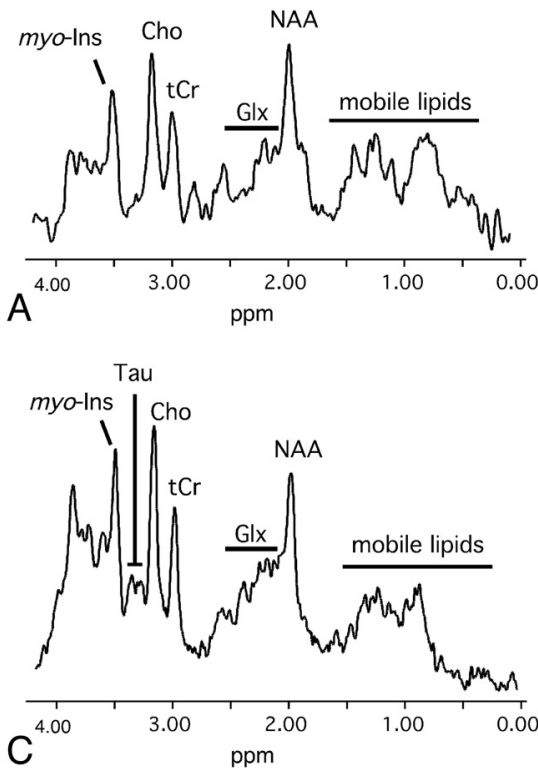

$\mathrm{TE}=135 \mathrm{~ms}$
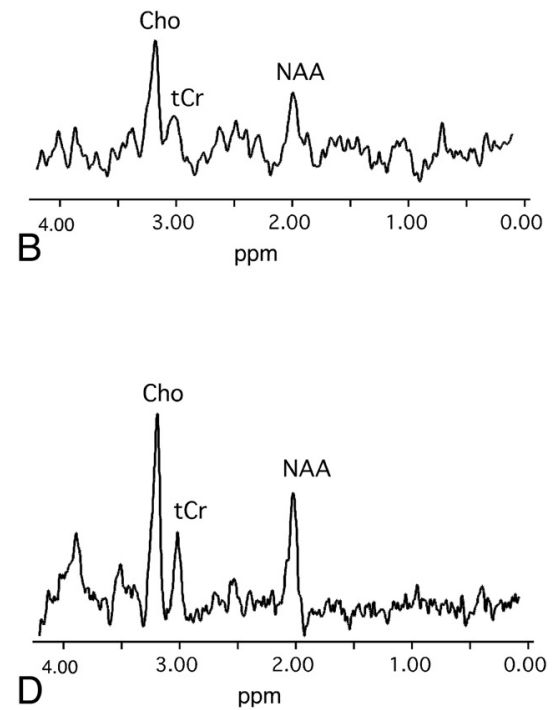

Fig 5. Typical brain ${ }^{1} \mathrm{H}-\mathrm{MR}$ spectra from a fetus and a PN obtained in the deep white matter. $A$ and $B, \mathrm{MR}$ spectra from a fetus in utero near term (GA $=36$ weeks). $C$ and $D$, MR spectra from a preterm neonate at term equivalent (PCA $=36$ weeks).

cally significant variations of mean ADC values were observed in the pons. A lower mean value was measured in the group of premature neonates $(-8 \%)$ compared with that found in fetuses (premature neonates, $0.98 \pm 0.02 \times 10^{-6} \mathrm{~mm}^{2} / \mathrm{s}$; fetuses, $1.07 \pm 0.02 \times 10^{-6} \mathrm{~mm}^{2} / \mathrm{s} ; P=.0008$; Table 1$)$. In the basal ganglia, the mean $\mathrm{ADC}$ value was also lower in the group of premature neonates (premature neonates, $1.21 \pm 0.01 \times$ $10^{-6} \mathrm{~mm}^{2} / \mathrm{s}$; fetuses, $1.26 \pm 0.02 \times 10^{-6} \mathrm{~mm}^{2} / \mathrm{s}$, respectively) without reaching statistical significance $(P=.0869$; Table 1$)$. Conversely, the mean ADC value in the parietal white matter was significantly higher in the group of premature neonates than in fetuses $(+6 \%$; premature neonates, $1.77 \pm 0.03 \times$ $10^{-6} \mathrm{~mm}^{2} / \mathrm{s}$; fetuses, $1.66 \pm 0.03 \times 10^{-6} \mathrm{~mm}^{2} / \mathrm{s}$, respectively; $P=.0172$; Table 1 ). In all other regions, both groups showed comparable ADC mean values.

\section{Comparison of Brain Metabolites between Fetuses and Premature Neonates}

Under identical MR spectroscopy conditions, the signal intensity-to-noise ratio of ex utero spectra seemed greater than in utero spectra (Fig 5) because the filling factor of the head coil was better than the body coil. At short TE, most of the ratios of metabolites to tissue water were increased in premature neonates in comparison with fetuses at short TE, whereas water mean ADC values were identical in the centrum semiovale of both groups (Table 1). The metabolic analysis of deep white matter (Figs 2 and 5 and Table 2) showed a trend for $\mathrm{Cho} / \mathrm{H}_{2} \mathrm{O}$ to be higher in the group of premature neonates than in the group of fetuses though the difference was not statistically significant $(P=.0858)$. Significant variations of $\mathrm{NAA} / \mathrm{H}_{2} \mathrm{O}, \mathrm{tCr} /$ $\mathrm{H}_{2} \mathrm{O}, \mathrm{Glx} / \mathrm{H}_{2} \mathrm{O}$, and $\mathrm{mIns} / \mathrm{H}_{2} \mathrm{O}$ were detected. All these metabolic ratios were significantly higher in the group of premature neonates compared with the group of fetuses $(+26 \%$ for $\mathrm{NAA} / \mathrm{H}_{2} \mathrm{O},+28 \% \mathrm{tCr} / \mathrm{H}_{2} \mathrm{O},+19 \%$ for $\mathrm{Glx} / \mathrm{H}_{2} \mathrm{O}$, and $+32 \%$ for $\mathrm{mIns} / \mathrm{H}_{2} \mathrm{O}$; Table 2). Unlike for the other metabolites, a lower lipids $/ \mathrm{H}_{2} \mathrm{O}$ ratio was measured in the group of premature neonates, though not reaching statistical significance (Figs 2 and 5 and Table 2). Among the other ratios of metabolites analyzed in this study (Table 3 ), significantly lower Cho/ tCr $(-11 \%)$ and higher mIns/Cho $(+24 \%)$ were obtained for premature neonates.

At long TE, no significant differences were observed between the group of fetuses and premature neonates for NAA/ $\mathrm{H}_{2} \mathrm{O}, \mathrm{tCr} / \mathrm{H}_{2} \mathrm{O}, \mathrm{Cho} / \mathrm{H}_{2} \mathrm{O}, \mathrm{NAA} / \mathrm{Cho}, \mathrm{NAA} / \mathrm{tCr}$, and $\mathrm{Cho} / \mathrm{tCr}$ 


\begin{tabular}{|c|c|c|c|}
\hline $\begin{array}{l}\text { Metabolite } \\
\text { Ratio }\end{array}$ & $\begin{array}{c}\text { Fetuses } \\
\left(n=20 \text { or } 19^{\mathrm{a}}\right)\end{array}$ & $\begin{array}{c}\text { PNs } \\
(n=20)\end{array}$ & $\begin{array}{c}\text { Unpaired } t \text { Test, } \\
P \text { Value }\end{array}$ \\
\hline \multicolumn{4}{|l|}{$\mathrm{TE}=30 \mathrm{~ms}$} \\
\hline $\mathrm{NAA} / \mathrm{H}_{2} \mathrm{O}$ & $2.19 \pm 0.19$ & $2.76 \pm 0.16$ & .0279 \\
\hline $\mathrm{tCr} / \mathrm{H}_{2} \mathrm{O}$ & $2.18 \pm 0.20$ & $2.80 \pm 0.16$ & .0184 \\
\hline Cho/ $\mathrm{H}_{2} \mathrm{O}$ & $2.98 \pm 0.21$ & $3.53 \pm 0.22$ & .0818 \\
\hline $\mathrm{Glx} / \mathrm{H}_{2} \mathrm{O}$ & $5.36 \pm 0.35$ & $6.38 \pm 0.29$ & .0324 \\
\hline $\mathrm{Tau} / \mathrm{H}_{2} \mathrm{O}$ & $0.56 \pm 0.09$ & $0.63 \pm 0.06$ & .6525 \\
\hline $\mathrm{mlns} / \mathrm{H}_{2} \mathrm{O}$ & $1.64 \pm 0.17$ & $2.17 \pm 0.17$ & .0332 \\
\hline Lipids $/ \mathrm{H}_{2} \mathrm{O}$ & $9.98 \pm 2.44$ & $7.28 \pm 0.65$ & .2986 \\
\hline \multicolumn{4}{|l|}{$\mathrm{TE}=135 \mathrm{~ms}$} \\
\hline $\mathrm{NAA} / \mathrm{H}_{2} \mathrm{O}$ & $2.00 \pm 0.22$ & $2.07 \pm 0.12$ & .7685 \\
\hline $\mathrm{tCr} / \mathrm{H}_{2} \mathrm{O}$ & $1.33 \pm 0.21$ & $1.30 \pm 0.07$ & .8697 \\
\hline Cho/ $\mathrm{H}_{2} \mathrm{O}$ & $3.50 \pm 0.20$ & $3.47 \pm 0.16$ & .8891 \\
\hline $\mathrm{Lac} / \mathrm{H}_{2} \mathrm{O}$ & $0.00 \pm 0.00$ & $0.00 \pm 0.00$ & \\
\hline
\end{tabular}

Note:-Data are mean \pm SEM.

a $n=20$ for a TE of $30 \mathrm{~ms}$ and 19 for TE of $135 \mathrm{~ms}$.

\begin{tabular}{lccc}
\hline \multicolumn{4}{l}{ Table 3: Comparison of ratios of metabolites in fetuses and PNs } \\
\hline $\begin{array}{l}\text { Metabolite } \\
\text { Ratio }\end{array}$ & $\begin{array}{c}\text { Fetuses } \\
\left(n=20 \text { or } 19^{\mathrm{a}}\right)\end{array}$ & $\begin{array}{c}\text { PNs } \\
(n=20)\end{array}$ & $\begin{array}{c}\text { Unpaired } t \text { Test, } \\
P \text { Value }\end{array}$ \\
\hline $\mathrm{TE}=30 \mathrm{~ms}$ & & & \\
$\mathrm{NAA} / \mathrm{Cho}$ & $0.73 \pm 0.05$ & $0.77 \pm 0.03$ & .3926 \\
$\mathrm{NAA} / \mathrm{Cr}$ & $1.02 \pm 0.06$ & $0.98 \pm 0.03$ & .5588 \\
$\mathrm{Cho} / \mathrm{tCr}$ & $1.39 \pm 0.06$ & $1.25 \pm 0.03$ & .0318 \\
$\mathrm{mlns} / \mathrm{tCr}$ & $0.75 \pm 0.06$ & $0.76 \pm 0.04$ & .8682 \\
$\mathrm{mlns} / \mathrm{Cho}$ & $0.55 \pm 0.05$ & $0.76 \pm 0.04$ & .0013 \\
$\mathrm{mlns} / \mathrm{NAA}$ & $0.75 \pm 0.06$ & $0.77 \pm 0.03$ & .7542 \\
Glx/tCr & $2.67 \pm 0.24$ & $2.36 \pm 0.13$ & .2594 \\
Glx/Cho & $1.93 \pm 0.16$ & $1.90 \pm 0.11$ & .9145 \\
Glx/NAA & $2.80 \pm 0.34$ & $2.40 \pm 0.14$ & .2868 \\
$\mathrm{TE}=135 \mathrm{~ms}$ & & & \\
NAA/Cho & $0.59 \pm 0.08$ & $0.60 \pm 0.03$ & .8463 \\
NAA/Cr & $1.74 \pm 0.32$ & $1.64 \pm 1.08$ & .8352 \\
Cho/tCr & $3.06 \pm 0.34$ & $2.73 \pm 0.12$ & .4597 \\
\hline
\end{tabular}

Note:-Data are mean \pm SEM.

$\mathrm{a} n=20$ for a TE of $30 \mathrm{~ms}$ and 19 for TE of $135 \mathrm{~ms}$.

(Table 2). Lactate was undetectable in the brain of fetuses and premature neonates (Fig 5 and Table 2).

\section{Discussion}

To our knowledge, the current study is the first to undertake a comparison of cerebral development between in utero fetuses and age-matched preterm neonates, based on a relatively large sample of subjects (48) examined across a very narrow time window (at $37 \pm 2$ weeks GA or PCA). This study provides new insight into brain maturation in terms of tissue microstructure and neurochemistry. Our metabolic and microstructural findings support the concept of acceleration in brain maturation in some cerebral regions after birth in healthy preterm neonates. ${ }^{18}$ This maturational acceleration is probably elicited by the combined effects of enteral feeding and early exposure to environmental stimuli.

Previous studies on both preterm and full term neonates have shown significant negative correlation between ADC values and gestational age. ${ }^{19,20}$ Indeed, diffusion parameters in the developing brain have been found to vary with water content, cell density, formation of white matter tracts, membrane potential, and myelination. ${ }^{3,6,21}$ Progressive decrease of ADC values in fetuses after 30 weeks $\mathrm{GA}^{3}$ and in preterm and term neonates ${ }^{19,20,22-24}$ has been putatively ascribed to a sequence of events making up the "premyelination stage" 25,26 and the initiation of myelination. Premyelination is a complex process that includes a reduction in total water content, a rise in lipid concentration, the proliferation and maturation of oligodendrocyte precursors, and the ensheathment of axons by premyelin. ${ }^{26}$ In the current study, the ADC values from different cerebral regions were comparable in both fetuses and premature neonates except for the pons and the parietal white matter. PNs surprisingly showed a higher ADC in their parietal white matter and a lower ADC in the pons. The higher ADC value in the parietal white matter indicates an increase in water diffusion probably related to subtle microstructural white matter anomalies, a common finding in the preterm brain, and possible gliosis. ${ }^{27,28}$ All the premature neonates in our study were born between 25 and 33 weeks GA, a developmental window of highest susceptibility to perinatal white matter injury, coinciding with the predominance in the parietal white matter of preoligodendrocytes particularly vulnerable to oxidative stress. ${ }^{29}$ The unexpected lower value points to a greater restriction in water diffusion, probably resulting from a modification in the organization of pontine white matter tracts, such as a thickening of the myelin sheet. Thus, this lower ADC probably reflects a more advanced maturational process in a key sensory motor relay in the premature brain after several weeks of extrauterine life. This finding is consistent with recent diffusion tensor imaging studies reporting increased fractional anisotropy in various cerebral white matter regions, including sensory tracts of premature neonates imaged at term equivalent compared with term neonates. ${ }^{18,30}$ This finding was ascribed to an accelerated white matter development due to environmental stimulation. ${ }^{18,30}$

Our metabolic findings reveal significant differences at short TE between in utero fetuses and premature neonates. Almost all metabolic ratios expressed with water tissue signal intensity as a reference were higher in the group of premature neonates. A possible explanation to this finding could have been related to a different content in tissue water in the centrum semiovale of fetuses and preterm neonates leading to a general increase in metabolite signal intensity in the premature population. However, this hypothesis does not seem supported by water $\mathrm{ADC}$ values in the centrum semiovale that were found identical in preterm neonates and fetuses. Moreover, the use of metabolic ratios expressed independently of tissue water content corroborated the finding of significant metabolic changes in the preterm brain that are unrelated to water content variations. Intriguingly, no difference was observed between fetuses and premature neonates at long TE. This finding could be explained by reduced signal intensityto-noise ratio at long TE due to T2 weighting. This result also could suggest the existence of a pool of metabolites with short T2 that would be greater in premature neonates than in fetuses. Transverse relaxation mechanisms may be influenced by different factors including cytoplasmic or intraorganelle viscosity, ${ }^{31}$ and metabolite-protein binding. ${ }^{32}$ The short T2 of a fraction of metabolites could be explained by the ultrastructural modifications occurring in neural cells during axon growth and myelination, such as the proliferation and enhanced capacity of mitochondria and accrued metabolite synthesis. ${ }^{33}$ Interestingly, a developmental increase in T2 values of 
metabolites has been found in the mouse developing brain, ${ }^{34}$ and in the human brain (NAA and Cho) from 32 to 42 weeks postconceptional age. ${ }^{16}$ So far, small pools of bound creatine ${ }^{35}$ or lactate $e^{36}$ have been detected in the adult brain but have not been investigated in the developing brain.

Most of our metabolic findings in premature neonates are consistent with the well-known progressive neurochemical changes occurring within the white matter during normal brain maturation. These modifications are characterized by an increase in NAA and in $\mathrm{tCr}$, and a reduction of mIns and Cho. ${ }^{8,10,12,14}$ Interestingly, these changes have been shown to occur more rapidly in premature neonates, ${ }^{37}$ a result in agreement with our own findings. The higher $\mathrm{NAA} / \mathrm{H}_{2} \mathrm{O}$ in premature neonates is suggestive of myelination progress and neuronal maturation. Indeed, this metabolite, essentially found in the somas and the axons of neurons is considered as a marker of neuronal function. ${ }^{38}$ It would be involved in myelin maintenance via the synthesis of lipids and myelin precursors in the oligodendrocyte. ${ }^{39}$ Interestingly, NAA has been identified in oligodendrocytetype 2 astrocyte progenitor cells and immature oligodendrocytes, ${ }^{40}$ which suggests that in the developing brain, NAA may not only reflect neuronal maturation but also myelination processes. ${ }^{41}$ Another difference between fetuses and premature neonates was the significant increase of the $\mathrm{Glx} / \mathrm{H}_{2} \mathrm{O}$ ratio in the latter group. The principal contributor to the Glx signal intensity in brain is glutamate, the main excitatory neurotransmitter, that is supplied to the neurons by the astrocytes in the form of its precursor, glutamine. ${ }^{42}$ An increase in white matter glutamate concentration concomitant with a reduction in glutamine has been reported in preterm neonates explored around term (at $41 \pm 1$ week PCA) compared with their first examination after birth (at $34 \pm 1$ week GA). ${ }^{10}$ Thus, the elevation of $\mathrm{Glx} / \mathrm{H}_{2} \mathrm{O}$ in our study may be ascribed to glutamate, an amino acid that has been shown to regulate the proliferation and maturation of oligodendrocyte progenitors. ${ }^{43}$ The rise in $\mathrm{tCr} / \mathrm{H}_{2} \mathrm{O}$ in premature neonates represents the increase of both creatine and phosphocreatine, 2 compounds involved in cell energy metabolism that are highly concentrated in glial cells. ${ }^{40}$ Together, the changes observed in NAA, Glx, and creatine point to an accelerated maturation in the centrum semiovale of premature neonates.

Unlike the changes in NAA, Glx, and creatine, the high $\mathrm{mIns} / \mathrm{H}_{2} \mathrm{O}$ and the trend for $\mathrm{Cho} / \mathrm{H}_{2} \mathrm{O}$ to be lower are rather unexpected because a progressive reduction of these compounds throughout brain maturation has constantly been reported. Myo-inositol is highly concentrated in astrocytes and therefore regarded as an astroglial marker. ${ }^{44}$ The increase in cerebral mIns $/ \mathrm{H}_{2} \mathrm{O}$ in premature neonates could be suggestive of gliosis. The main contributors to the choline resonance in brain are glycerophosphocholine and phosphocholine, 2 intermediates of the phosphatidylcholine pathway. ${ }^{45}$ Their increase has essentially been reported in brain tumors and diseases characterized by myelin alterations. ${ }^{45-47}$ The abnormal $\mathrm{ADC}$ value in the parietal white matter together with the increase in $\mathrm{Cho} / \mathrm{H}_{2} \mathrm{O}$ and $\mathrm{mIns} / \mathrm{H}_{2} \mathrm{O}$ in the centrum semiovale indicate the existence of subtle white matter injury and gliosis not visible by conventional MR imaging.

\section{Conclusions}

Our study reveals an acceleration of maturation in some cerebral regions in healthy premature neonates compared with age-matched fetuses that is structurally and metabolically manifest and consistent with progress in myelination and stimulation of neuronal function. However, these maturational processes are concomitant with changes in white matter microstructure and neurochemistry both evocative of subtle tissue injury and probable gliosis. Further studies are required to assess the evolution of these white matter anomalies. Our study indicates that intra- and extrauterine brain maturations around term may not be equivalent and that MR imaging and MR spectroscopy data from premature brains are not appropriate for the understanding of in utero fetal cerebral maturation.

Disclosures: J.F. Schneider, Research Support: Walter und Margarete Liechtenstein Stiftung

\section{References}

1. Miller SP, Vigneron DB, Henry RG, et al. Serial quantitative diffusion tensor MRI of the premature brain: development in newborns with and without injury. J Magn Reson Imaging 2002;16:621-32

2. Huppi PS, Warfield S, Kikinis R, et al. Quantitative magnetic resonance imaging of brain development in premature and mature newborns. Ann Neurol 1998; 43:224-35

3. Schneider JF, Confort-Gouny S, Le Fur Y, et al. Diffusion-weighted imaging in normal fetal brain maturation. Eur Radiol 2007;17:2422-29

4. Bydder GM, Rutherford MA. Diffusion-weighted imaging of the brain in neonates and infants. Magn Reson Imaging Clin N Am 2001;9:83-98, viii

5. Huppi PS, Murphy B, Maier SE, et al. Microstructural brain development after perinatal cerebral white matter injury assessed by diffusion tensor magnetic resonance imaging. Pediatrics 2001;107:455-60

6. Prayer D, Barkovich AJ, Kirschner DA, et al. Visualization of nonstructura changes in early white matter development on diffusion-weighted MR images: evidence supporting premyelination anisotropy. AJNR Am J Neuroradiol 2001;22:1572-76

7. Cecil KM. MR spectroscopy of metabolic disorders. Neuroimaging Clin N Am 2006;16:87-116, viii

8. Kreis R, Ernst T, Ross BD. Development of the human brain: in vivo quantification of metabolite and water content with proton magnetic resonance spectroscopy. Magn Reson Med 1993;30:424-37

9. Brighina E, Bresolin N, Pardi G, et al. Human fetal brain chemistry as detected by proton magnetic resonance spectroscopy. Pediatr Neurol 2009;40:327-42

10. Kreis R, Hofmann L, Kuhlmann B, et al. Brain metabolite composition during early human brain development as measured by quantitative in vivo $1 \mathrm{H} \mathrm{mag-}$ netic resonance spectroscopy. Magn Reson Med 2002 48:949-58

11. Heerschap A, van den Berg PP. Proton magnetic resonance spectroscopy of human fetal brain. Am J Obstet Gynecol 1994;170:1150-51

12. Girard N, Gouny SC, Viola A, et al. Assessment of normal fetal brain maturation in utero by proton magnetic resonance spectroscopy. Magn Reson Med 2006;56:768-75

13. Girard N, Fogliarini C, Viola A, et al. MRS of normal and impaired fetal brain development. Eur J Radiol 2006;57:217-25

14. Kok RD, van den Berg PP, van den Bergh AJ, et al. Maturation of the human fetal brain as observed by 1 H MR spectroscopy. Magn Reson Med 2002;48: 611-16

15. Kok RD, van den Bergh AJ, Heerschap A, et al. Metabolic information from the human fetal brain obtained with proton magnetic resonance spectroscopy. Am J Obstet Gynecol 2001;185:1011-15

16. Cady EB, Penrice J, Amess PN, et al. Lactate, $\mathrm{N}$-acetylaspartate, choline and creatine concentrations, and spin-spin relaxation in thalamic and occipitoparietal regions of developing human brain. Magn Reson Med 1996;36:878-86

17. Vanhamme L, van den Boogaart A, Van Huffel S. Improved method for accurate and efficient quantification of MRS data with use of prior knowledge. $J$ Magn Reson 1997;129:35-43

18. Gimenez M, Miranda MJ, Born AP, et al. Accelerated cerebral white matter development in preterm infants: a voxel-based morphometry study with diffusion tensor MR imaging. Neuroimage 2008;1 41:728-34

19. Morriss MC, Zimmerman RA, Bilaniuk LT, et al. Changes in brain water diffusion during childhood. Neuroradiology 1999;41:929-34

20. Neil JJ, Shiran SI, McKinstry RC, et al. Normal brain in human newborns: apparent diffusion coefficient and diffusion anisotropy measured by using diffusion tensor MR imaging. Radiology 1998;209:57-66 
21. Prayer D, Prayer L. Diffusion-weighted magnetic resonance imaging of cerebral white matter development. Eur J Radiol 2003;45:235-43

22. Dudink J, Kerr JL, Paterson K, et al. Connecting the developing preterm brain. Early Hum Dev 2008;84:777-82

23. Mukherjee P, Miller JH, Shimony JS, et al. Normal brain maturation during childhood: developmental trends characterized with diffusion-tensor MR imaging. Radiology 2001;221:349-58

24. Tanner SF, Ramenghi LA, Ridgway JP, et al. Quantitative comparison of intrabrain diffusion in adults and preterm and term neonates and infants. $A J R$ Am J Roentgenol 2000;174:1643-49

25. Wimberger DM, Roberts TP, Barkovich AJ, et al. Identification of "premyelination" by diffusion-weighted MRI. J Comput Assist Tomogr 1995;19:28-33

26. Back SA, Luo NL, Borenstein NS, et al. Arrested oligodendrocyte lineage progression during human cerebral white matter development: dissociation between the timing of progenitor differentiation and myelinogenesis. J Neuropathol Exp Neurol 2002;61:197-211

27. Neil J, Miller J, Mukherjee P, et al. Diffusion tensor imaging of normal and injured developing human brain-a technical review. NMR Biomed 2002;15:543-52

28. Hagen T, Ahlhelm F, Reiche W. Apparent diffusion coefficient in vasogenic edema and reactive astrogliosis. Neuroradiology 2007;49:921-26

29. Back SA, Luo NL, Borenstein NS, et al. Late oligodendrocyte progenitors coincide with the developmental window of vulnerability for human perinatal white matter injury. J Neurosci 2001;21:1302-12

30. Rose SE, Hatzigeorgiou X, Strudwick MW, et al. Altered white matter diffusion anisotropy in normal and preterm infants at term-equivalent age. Magn Reson Med 2008;60:761-67

31. Lopez-Beltran EA, Mate MJ, Cerdan S. Dynamics and environment of mitochondrial water as detected by 1H NMR. J Biol Chem 1996;271:10648-53

32. Murphy PS, Leach MO, Rowland IJ. Signal modulation in (1)H magnetic resonance spectroscopy using contrast agents: proton relaxivities of choline, creatine, and N-acetylaspartate. Magn Reson Med 1999;42:1155-58

33. Erecinska M, Cherian S, Silver IA. Energy metabolism in mammalian brain during development. Prog Neurobiol 2004;73:397-445

34. Larvaron P, Bielicki G, Boespflug-Tanguy O, et al. Proton MRS of early postnatal mouse brain modifications in vivo. NMR Biomed 2006;19:180-87
35. Helms G, Frahm J. Magnetization transfer attenuation of creatine resonances in localized proton MRS of human brain in vivo. NMR Biomed 1999;12:490-94

36. Luo Y, Rydzewski J, de Graaf RA, et al. In vivo observation of lactate methy proton magnetization transfer in rat C6 glioma. Magn Reson Med 1999;41: 676-85

37. Huppi PS, Posse S, Lazeyras F, et al. Magnetic resonance in preterm and term newborns: 1H-spectroscopy in developing human brain. Pediatr Res 1991;30:574-78

38. Moffett JR, Ross B, Arun P, et al. N-Acetylaspartate in the CNS: from neurodiagnostics to neurobiology. Prog Neurobiol 2007;81:89-131

39. Chakraborty G, Mekala P, Yahya D, et al. Intraneuronal N-acetylaspartate supplies acetyl groups for myelin lipid synthesis: evidence for myelin-associated aspartoacylase. J Neurochem 2001;78:736-45

40. Urenjak J, Williams SR, Gadian DG, et al. Proton nuclear magnetic resonance spectroscopy unambiguously identifies different neural cell types. J Neurosci 1993;13:981-89

41. Bhakoo KK, Pearce D. In vitro expression of $\mathrm{N}$-acetyl aspartate by oligodendrocytes: implications for proton magnetic resonance spectroscopy signal in vivo. J Neurochem 2000;74:254-62

42. Bak LK, Schousboe A, Waagepetersen HS. The glutamate/GABA-glutamine cycle: aspects of transport, neurotransmitter homeostasis and ammonia transfer. J Neurochem 2006;98:641-53

43. Gallo V, Zhou JM, McBain CJ, et al. Oligodendrocyte progenitor cell proliferation and lineage progression are regulated by glutamate receptor-mediated K+ channel block. J Neurosci 1996;16:2659-70

44. Brand A, Richter-Landsberg C, Leibfritz D. Multinuclear NMR studies on the energy metabolism of glial and neuronal cells. Dev Neurosci 1993;15:289-98

45. Boulanger Y, Labelle M, Khiat A. Role of phospholipase A(2) on the variations of the choline signal intensity observed by $1 \mathrm{H}$ magnetic resonance spectroscopy in brain diseases. Brain Res Brain Res Rev 2000;33:380 - 89

46. Farooqui AA, Horrocks LA, Farooqui T. Glycerophospholipids in brain: thei metabolism, incorporation into membranes, functions, and involvement in neurological disorders. Chem Phys Lipids 2000;106:1-29

47. Klein J. Membrane breakdown in acute and chronic neurodegeneration: focus on choline-containing phospholipids. J Neural Transm 2000;107:1027-63 